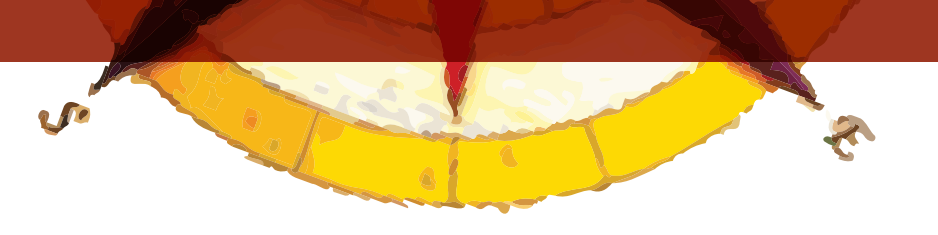

\title{
METROPOLIZACIÓN Y SUSTENTABILIDAD: DESAFÍOS ACTUALES PARA LA EDUCACIÓN GEOGRÁFICA AMBIENTAL
}

\author{
Fabián Araya Palacios ${ }^{59}$ \\ Edelmira González González ${ }^{60}$
}

\section{RESUMEN}

Este artículo presenta un marco teórico y metodológico que integra los fenómenos de metropolización y sustentabilidad con el proceso educativo, especialmente con la denominada educación geográfica Ambiental. Se refiere tanto a la génesis del proceso de metropolización, presentando algunos avances que permiten convertir a la metrópoli en sustentable, a la vez que presenta problemáticas ambientales urbanas que pueden ser desarrolladas por los docentes de la educación en los distintos niveles del proceso enseñanza-aprendizaje.

Palabras clave: Educación Geográfica, Didáctica de la Geografía, Metropolización, Sustentabilidad.

\begin{abstract}
This article presents a theoretical and methodological frame that integrates the urban development phenomena and sustainability with the educational process, especially with the so called environmental geographical education. It refers so much to the genesis of the process of metropolization, presenting some advances that they allow to convert to the urban areas in sustainability, simultaneously that presents problematic environmental urban that education - learning can be developed by the teachers of the education in the different levels of the process.
\end{abstract}

Keys words: Geographic Education, Didactics of Geography, Metropolization, Sustainability.

\section{INTRODUCCIÓN}

El interés por las temáticas medio ambientales se ha generalizado de tal modo que hoy en día afecta a casi todas las áreas científicas e incluso atañe a las más diversas esferas de la vida cotidiana. Dentro de este contexto la educación desde un principio, ha jugado un papel preponderante siendo posiblemente una de las tareas sociales que mayor protagonismo ha tenido en el diálogo científico.

59 Docente del Departamento de ciencias sociales de la Universidad de la Serena - Chile.

60 Académica pensionada de la Universidad de La Serena - Chile. 
Sin lugar a dudas, el ambiente ofrece a la educación múltiples posibilidades temáticas que pueden ser incorporadas y desarrolladas metodológicamente, a través de una visión sistémica de la realidad espacial. Surge así la educación geográfica ambiental que concibe lo educativo-ambiental como objeto de estudio teórico, metodológico, histórico, axiológico, etc.

Las metrópolis, poseen una enorme posibilidad de utilización educativa por parte de los docentes, por cuanto, entre otras razones, presenta gran complejidad y dinamismo, por el rol que poseen como articuladores del territorio, por su propia evolución histórica, por ser crisol de la cultura y cuna de decisiones, así como por las múltiples interconexiones que en ellas se generan y de la cual disfrutan sus moradores.

Es preciso considerar al fenómeno urbano como agente educativo de primer orden, que cumple históricamente un protagonismo enraizado en el propio devenir vital de sus habitantes. Bajo este contexto, la ciudad se trasforma en un fenómeno básico para analizar y sistematizar las múltiples formas de interrelación de la población y su medio ambiente.

Identificar, conocer, explicar y valorar la multiplicidad de las dimensiones contenidas en el fenómeno urbano ayuda a generar modelos axiológicos de vida y a entender los cambios generados por la globalización. El docente, a través de la educación geográfica ambiental puede introducir a sus alumnos en el estudio de las ciudades desde dos perspectivas:

En primer lugar, la enseñanza-aprendizaje a partir del medio urbano circundante y externo. Esta perspectiva se caracteriza por utilizar el entorno en que vive el alumno como medio estimulante y organizador del trabajo escolar (objeto de estudio).

En segundo lugar, la enseñanza-aprendizaje del medio urbano interno. En esta perspectiva se destacan estrategias tales como: modelos de simulación urbana, itinerarios urbanos, creación e implantación de diseños ambientales de equipamiento e instalaciones urbanas diversas. Por ejemplo: centro de acción, proyectos de diseño ambiental etc. (aspectos estéticos).

De acuerdo a la perspectiva adoptada, el docente a través de la denominada Pedagogía Urbana puede conducir e introducir a sus alumnos de una manera vivencial, en la comprensión de los distintos procesos, problemas ambientales que se presentan hoy en las ciudades.

Este artículo presenta un marco teórico y metodológico que une el fenómeno de la metropolización con el proceso educativo y en especial con la educación geográfica ambiental. Se refiere tanto a la génesis del proceso de metropolización, presentando algunos avances que permiten convertir a la metrópoli en sustentable, a la vez que presenta problemáticas ambientales urbanas que pueden ser desarrolladas por los docentes de la educación, en los distintos niveles del proceso enseñanzaaprendizaje.

\section{EDUCACIÓN GEOGRÁFICA AMBIENTAL}

Un antecedente de gran importancia para comprender la relación entre educación geográfica y medio ambiente, lo constituye la obra de Diana Durán, Cecilia Daguerre y Albina Lara titulada "Los cambios mundiales y la enseñanza de la geografia" (1996). El libro contiene un capítulo relacionado con el medio ambiente, el desarrollo sustentable y la importancia de integrar estos contenidos en la 
enseñanza de la geografía. "Una de las premisas básicas del desarrollo sustentable es el reconocimiento de que el ambiente y el desarrollo son complementarios e interdependientes y, en el largo plazo, se refuerzan mutuamente" (Durán et.al, 1996:137). Las autoras proponen que los problemas ambientales funcionan como un sistema. Por lo tanto, se requiere un conjunto coherente de soluciones que aseguren que cada medida que se toma, tanto en el planeamiento como en la implementación, se articule perfectamente dentro de un sistema.

La preocupación de la educación geográfica por los problemas ambientales, tanto en ámbitos urbanos como rurales, son tratados de forma muy precisa en el texto "El crepúsculo de la buena tierra: raíces geográficas de la educación ambiental" (2000) de la profesora Diana Durán. En este y en otros trabajos la autora realiza un esfuerzo interdisciplinario para vincular la educación geográfica y la educación ambiental (Durán, 2005; 2010). La preocupación de ambas disciplinas se presentaba, tradicionalmente, por caminos separados. Este trabajo produce una convergencia en la preocupación por relacionar los problemas ambientales con el espacio geográfico. "Este libro plantea la necesidad de conocer la buena tierra y de saber geografia para acercarse a la resolución de los problemas ambientales que nos acucian" (Durán, 2000:9). A través de estas obras, se aprecia el interés de investigadores, geógrafos y docentes de geografía, en torno al estudio del espacio geográfico y las problemáticas ambientales que lo afectan.

Entre 2006 y 2009 se han publicado monográficos elaborados por varios autores, en los cuales la participación de académicos latinoamericanos ha sido destacada. Esta manera colectiva de publicar, permite abrir nuevas sendas de colaboración entre académicos de diversas nacionalidades.

Una obra colectiva se publicó en Australia en el seno de la Unión Geográfica Internacional en 2006. El titulo es "Geographical Education in a Changing World: Past Experience, Current Trends and Future Challenges", editados por John Lidstone y Michael Williams. Esta obra constituye una visión panorámica a nivel mundial de la situación de la educación geográfica. Se encuentra organizada de acuerdo a los diversos continentes de los cuales provienen los autores. En América Latina se invitó a participar a representantes de Brasil, Argentina, Venezuela y Chile, los cuales entregaron un diagnóstico de la educación geográfica en sus respectivos países.

Un segundo monográfico corresponde a la revista Didáctica Geográfica, editada en España en 2007, bajo el alero del grupo de Didáctica de la Geografía de la Asociación de Geógrafos Españoles. Esta obra estuvo dedicada a la geografía y la educación para la ciudadanía, fue coordinado por Xosé Manuel Souto González. Los países representantes de América Latina fueron Colombia, Venezuela, Brasil, Argentina y Chile.

Un tercer monográfico corresponde a un número especial de Research in Geographic Education, publicado en el primer semestre de 2008 por Texas State University-San Marcos Estados Unidos. Este número está dedicado a dar a conocer algunos de los trabajos presentados en Geoamericas Conference, evento desarrollado en la Ciudad de La Serena-Chile en 2007. En este número se encuentran dos presentaciones de investigadores chilenos y venezolanos (Muñiz, 2007).

En Agosto de 2008, se publicó un cuarto monográfico dedicado a la educación geográfica en la revista Novedades Educativas de Argentina. Se denomina "Geografia: Nuevas Miradas, Nuevos Sentidos" y presenta un conjunto de trabajos muy interesantes dedicados a diversos tópicos de la educación 
geográfica. Destaca en el monográfico la relación entre enseñanza de la geografía y uso de nuevas tecnologías de la información y también la relación entre geografía y educación ambiental (Ruiz, 2008).

Como se puede apreciar, el camino ha sido largo y complejo. Sin embargo, paulatinamente, se ha ido conformando una base teórica y práctica que está sentando las bases para una apropiada proyección de la educación geográfica ambiental.

\section{ANTECEDENTES DEL PROCESO DE METROPOLIZACIÓN}

Uno de los aspectos más destacados de la transformación territorial urbana experimentada por América Latina, conjuntamente con el rápido incremento de la tasa de urbanización, es el ritmo de crecimiento de las llamadas aglomeraciones de carácter metropolitano. Cada vez más, la población urbana tiende a concentrarse en ciudades de gran tamaño, denominadas metrópolis, ciudades cuyo tamaño excede al millón de habitantes.

Históricamente las ciudades han sido los centros de gobierno y de comercio, en algunos casos coinciden la localización de ellas en puertos. Son además centros intelectuales por excelencia, ubicándose en ellas las mejores universidades del país así como cines, teatros, salas de espectáculos, y más que todo en los últimos años se han visto en ellas proliferar grandes Mall y centros comerciales.

Las metrópolis son a la vez el asiento de los grandes centros financieros y bancarios de la economía nacional. De igual modo se localizan en ellas grandes aeropuertos, conectándolas con el resto del país y con el mundo entero. Una gran gama de servicios están ampliamente representados en las metrópolis, en ellas se encuentran establecimientos educacionales desde los niveles más bajos a los superiores, de igual modo cuentan con centros asistenciales y hospitalarios con tecnología de ultima generación, al igual que son centros de oficinas profesionales diversas, por lo que la actividad terciaria tiene en ellas un gran significado.

La presencia de estas características en las metrópolis han generado en la mayoría de ellas una corriente migratoria proveniente de otras ciudades ya sean estas intermedias o menores, produciendo en ellas por lo tanto, un crecimiento vertiginoso de su población, pasando a conformarse el llamado proceso de macrocefalia por lo que la ciudad metropolitana tiene más del doble o triple de las ciudades de gran tamaño que le siguen en importancia dentro del sistema nacional urbano.

\section{RESEÑA HISTÓRICA DEL PROCESO DE METROPOLIZACIÓN}

Hacia el año cuatro mil antes de cristo se inicio la denominada segunda revolución cultural o revolución urbana, la que se iniciaría simultáneamente en los valles de la región del bajo Nilo y la baja Mesopotamia. En América precolombina la urbanización se inició varios siglos más tarde en torno a lo cual se han conformado varias hipótesis tales como, bajo nivel cultural de los grupos procedentes de Asia, tardanza en la gestación de grupos capaces de conformar sociedades tecnológicas y generar excedentes para el intercambio.

Las primeras aldeas permanentes aparecieron unos mil quinientos años antes de Cristo. A lo largo del primer milenio las aldeas experimentaron una mayor expansión poblacional, debido a la 
adopción del maíz como fuente de alimentación, la posterior utilización del sistema de riego y de cultivo en chinampas, el desarrollo de técnicas apropiadas de cultivos itinerantes (Milpas o Rozas), hicieron posible la concentración de población en algunas áreas como por ejemplo la costa del Perú y meseta central de México.

Las primeras concentraciones de población en América, a las que se les puede llamar ciudades son en Mesoamérica: Teotihuacan, La Venta, de la cultura Chichimeca, Tajin de la cultura Totonaca, Monte Alban de la cultura Zapoteca, Tikal, Uaxanetún y Copán pertenecientes a la cultura Maya.

En Sudamérica, las concentraciones urbanas no alcanzaron ni la escala ni la población de América, sin embargo se deben mencionar como centros urbanos los existentes en la costa del Perú y el las Áreas cercanas al Lago Titi Caca. Destacándose el centro urbano-religioso Machu Pichu. E1 auge de las ciudades americanas coincidió con la decadencia de las europeas, es así como el Cuzco estaba en pleno desarrollo cuando Colón llegó a América. Algunos historiadores señalan que a la llegada de los españoles existían alrededor de cuarenta centros con carácter urbano, ya sea que se presentaban como centros de intercambio comercial, sedes de gobierno etc.

Se debe esperar hasta la época de la conquista española para el surgimiento de ciudades con funciones más diversas, ya que la fundación de ciudades fue el instrumento utilizado por la corona para consolidar la administración de América. En América podemos distinguir tres tipos de ciudades según su origen y función; algunas tuvieron su origen en la ocupación de asentamientos indígenas, como es el caso de ciudad de México; otras deben su origen a la explotación minera como Potosí y Oruro (Bolivia), Huancavelica en Perú, Cuenca en Ecuador, Guanajuato y Zacatecas en México y finalmente otro grupo de ciudades vieron su origen por ser asiento de puertos, creados por la necesidad de mantener las comunicaciones y el flujo de bienes tales como Cartagena de Indias, Veracruz y Callao. Durante la época colonial se deben mencionar también ciudades como Lima La Habana, Buenos Aires, Santiago de Chile, Quito, Bogotá, Caracas, Panamá y Ciudad de Guatemala.

A partir del siglo XVIII los cambios sociales y políticos vinculados a la emancipación americana, a las demanda de productos y al avance del transporte terrestre generaron en casi toda la región la fundación de numerosas ciudades de segundo orden subordinadas a las capitales, cristalizándose así un incipiente sistema urbano a partir del siglo XIX.

E1 siglo XX América Latina lo inicia siendo un continente eminentemente rural. En 1920 solo el 2,3\% de la población habitaba en ciudades, pero en el transcurso de él esta cifra cambio considerablemente alcanzando en 1987 un valor de 67\% de población Urbana. En 1920 las ciudades albergaban 2 millones de personas, en tanto en 1980 esta cifra alcanzó a 25, 2 millones de personas, es decir en sesenta años la población urbana de América latina se multiplicó por doce. Parte del continente está urbanizado o se está urbanizando de manera más acelerada que los países industrializados, en el periodo inicial de su desarrollo. Entre 1940 y 1950 doce países de la región tuvieron tasas promedio de crecimiento urbano equivalente a $4,5 \%$ anual, mientras que en nueve países europeos, durante su más alto periodo de crecimiento alcanzaron una tasa de solo $2,1 \%$ es así como el proceso de urbanización en América Latina desde sus inicios hasta hoy en día ha presentado caracteres muy sui generis, que hace necesario su análisis a fin de permitir la comprensión del sistema urbano actual. 


\section{IMPLICANCIAS ESPACIALES DEL PROCESO DE METROPOLIZACIÓN}

Toda actividad, evento o proceso genera impactos sobre el espacio en el cual se desarrolla, sean éstos de tipo positivo y/o negativo, dependiendo del grado de desarrollo que éste alcance y del grado de compromiso con el territorio que lo sustenta. Usualmente al proceso de urbanización, se le atribuye una serie de problemas de índole negativo, que si bien existen, no son los únicos, sino que también genera implicancias positivas, asociadas al grado de desarrollo del país en el cual se presentan.

Con un territorio de casi 20 millones de kilómetros cuadrados, la región latinoamericana pone de manifiesto una desigual modalidad de ocupación. Se ha sostenido en relación a las características generales de su ocupación que el territorio está sub-ocupado con una notable concentración de la población en una escasa superficie. No obstante los avances de carácter tecnológico y comunicacional ocurridos en los últimos años, esta situación se mantiene aún vigente.

Esta realidad de vacíos demográficos se aprecia por ejemplo, al constatar que en 1970, un 20\% por ciento de la superficie total registraba menos del $1 \%$ de población, al igual que las zonas ocupadas, más de 50 habitantes por $\mathrm{km}^{2}$ representaban el $5 \%$ del territorio, albergando el $40 \%$ de la población total.

Se debe tener presente que la desigual distribución de la población se hace más notable aún si se consideran las diferentes extensiones territoriales de los países involucrados como Brasil, con 8,5 millones de $\mathrm{km}^{2}$ concentra el $42 \%$ del territorio nacional, mientras que el Salvador con una superficie cercana a $21.000 \mathrm{~km}^{2}$ solo representa el $1 \%$ del territorio nacional.

Un análisis de la densidad demográfica por países entrega una visión preliminar del fenómeno, que puede ser considerado como punto de partida para análisis posteriores. Se observa una muy desigual distribución de los valores relativos a la densidad poblacional. Pero quizás el fenómeno demográfico más significativo de analizar para entender el fenómeno de la metropolización Latinoamericana es el denominado "concentrador" de grandes masas de población en focos del territorio el cual en algunos países alcanza índices promedio superior a 20 mil habitantes por $\mathrm{km} 2$.

Podemos identificar en Latinoamérica ciudades millonarias que han originado aglomeraciones metropolitanas, los que a su vez conforman las grandes áreas metropolitanas de las principales capitales de los países latinoamericanos. Entre las áreas metropolitanas que se han conformado por procesos de conurbación podemos citar el área metropolitana de Lima integrada por distritos tales como Lima, Bretaña, Chorrillos, La Victoria, Lince, Magdalena del Mar, Magdalena Vieja, Miraflores, Rimac, San Martín, San José del Surco y Surquillo entre otras.

El área metropolitana de Santiago de Chile constituida por comunas tales como Santiago, Independencia, Recoleta, Estación Central, Conchalí, Quinta Normal, Cerro Navia, Lo Prado, Cerri1los, La Cisterna, Lo Espejo, el Bosque, la Granja, San Ramón, San Miguel, San Joaquín, Nuunoa, Macul, La Reina, Providencia, Las Condes, Vitacura, Huechuraba, Renca, Peñalolen, Maipú, entre otros.

Un fenómeno importante de analizar en el estudio del proceso de metropolización latinoamericano es la concentración de la población en la denominada ciudad primada dentro del sistema 
nacional urbano. La aplicación de un índice sintético de la norma rango-tamaño o redes urbanas latinoamericanas, implica la proporción de residentes urbanos que deben moverse de una ciudad a otra para adecuarse a una distribución de logaritmo normal, presenta valores medios altos y una tendencia a un sostenido incremento.

Otro aspecto que merece especial atención para el caso de América Latina, es el hecho que su población ha perdido su carácter predominantemente rural, para adquirir una creciente fisonomía urbana. Por otra parte, una serie de factores específicos han contribuido a que las ciudades, producto del proceso de urbanización, resulten particularmente ventajosas para la localización de las actividades industriales y de servicios. El proceso hacia un mercado más amplio, mejor dotación de infraestructura, fuerza de trabajo aglomerada, localización del poder político nacional, funcionamiento de mecanismos de intermediación financiera, presencia de productores que actúan como proveedores y demandantes de insumos, al igual que la presencia de economías de escala debido a indivisibilidades tecnológicas, son algunas de las implicancias espaciales generadas por el proceso de urbanización en los territorios en que se presenta.

Se ha podido detectar, por otra parte, que el proceso de concentración, aunque ha mostrado variaciones, tiende a retroalimentarse generando condiciones favorables al momento de las escalas de producción y a la elevación de la productividad. En Brasil, por ejemplo, se ha detectado que a medida que crece el tamaño de la ciudad aumenta la diversificación de la estructura económica, se amplia el tamaño medio de las empresas y además, la productividad del trabajo en las industrias se eleva como resultado del incremento en la relación capital-mano de obra y de la existencia de economías de escala.

Se debe tener presente, sin embargo, que si el punto de vista del proceso de acumulación, la concentración espacial resulta funcional y positiva, es importante tener presente y no desconocer que el "gigantesco concentrador" ha ocasionado a la vez una serie de implicaciones espaciales negativas, que como se expresó anteriormente son los más mencionados y puestos en evidencia por los autores estudiosos del proceso de urbanización.

Dada la complejidad de impactos y consecuencias del proceso y con fines estrictamente metodológicos, es posible agrupar a éstas en dos grandes aspectos. Por un lado, los problemas derivados del ritmo de crecimiento de los centros urbanos y por otro, los relacionados con el tamaño de los centros urbanos y su poder concentrador.

En relación a los problemas asociados a la velocidad del crecimiento urbano se debe tener presente que se observa que existe una discordancia entre el ritmo de crecimiento poblacional urbano y las demandas creadas por dicha población, especialmente de servicios, fuente de ocupación y vivienda, siendo estas últimas mayores. Una consecuencia del cúmulo de necesidades y demandas insatisfechas ha sido la formación de barrios marginales o áreas marginales urbanas, fenómeno presente en toda América Latina.

En estas áreas se concentran proporciones importantes de población que por sus ingresos no logran acceder a viviendas adecuadas. La crisis de la vivienda se expresa en un déficit cuantitativo creciente del número de viviendas y en el nivel de deterioro físico de ellas. Se suma a esta carencia de viviendas, el déficit en infraestructura, ya que estas áreas carecen de agua potable, alcantarillado, luz eléctrica, así como aceras y calles pavimentadas. Por otra parte las demandas de atención hos- 
pitalaria, resultan la mayor de las veces insuficientes así también la demanda educacional no se ve satisfecha en forma satisfactoria.

Al igual se observa, producto de la escasez de tierras urbanas, un déficit de áreas verdes e instalaciones deportivas y culturales que afecta a toda la población de las ciudades que crece con un ritmo vertiginoso. Por lo que respecta a los problemas derivados del gran tamaño que alcanzan las metrópolis y la concentración de actividades que ello implica es importante señalar algunas de ellas.

Quizás el problema más representativo y que engloba a otros, es el denominado economías de aglomeración. Cuando una ciudad es pequeña o mediana, el costo medio por habitante para mantener sus servicios de transporte, agua potable, luz etc., es menor que cuando la ciudad es mayor, es lo que ha convenido en denominarse costos de urbanización. Aunque la creación de economías de escala abarata los costos de prestación de servicios, este proceso tiene un límite más allá del cual los costos se hacen manejables.

La extensión de las ciudades y su crecimiento incontrolado ha ocasionado en la mayoría de las metrópolis problemas de transporte urbano; cada vez se hace más difícil el viaje residencia-trabajo, con un desgaste físico y emocional significativo, a su vez, se ha requerido efectuar grandes inversiones en la construcción de autopistas y vías rápidas, por parte del estado o vía concesiones.

Los altos niveles de contaminación son otro problema presente en las metrópolis. La concentración demográfica e industrial, el alto número de automóviles etc., elevan considerablemente la concentración de gases y partículas, deteriorando la calidad de vida de los habitantes citadinos. A su vez ayuda a este deterioro, causado por contaminación, las aguas residuales de la industria y de hogares. Frente a los grandes volúmenes de desechos los sistemas de limpieza se vuelven incapaces de efectuar los procesos de reciclaje y casi todas las ciudades metropolitanas de Latinoamérica son atravesadas por cauces de ríos en su mayor parte contaminados, tal es el caso del Mapocho y Zanjón de la Aguada en Santiago o el Rimac en Lima.

Otro grupo de problemas, relacionado con el fenómeno concentrador es la segregación socio espacial. Se ha producido una competencia por la tierra y una especulación de precios, la cual produce segregación y conformación de barrios "exclusivistas" tales como Las Condes y La Dehesa en Santiago; Miraflores en Lima; Palermo en Buenos Aires; Bellavista en el centro norte de Quito, etc.

La existencia de estas áreas genera tensiones entre los habitantes de bajos ingresos o de ingresos ínfimos, produciéndose cada vez más crecientes tasas de criminalidad, secuestros, robos en diversos barrios metropolitanos, etc. Estas otras implicancias espaciales negativas también se hacen presente en las metrópolis de América Latina, situación que debe ser superada a través de una planificación integral, teniendo presente que actualmente más del $80 \%$ de su población residirá en ciudades.

Las consideraciones presentadas en este articulo, tanto de las características del fenómeno, así como de sus implicancias, dejan en claro que el fenómeno de la metropolización está presente en América Latina, por lo cual, en el umbral de la segunda década del siglo XXI la urbanización será el modo de vida de una gran parte de la población y por lo tanto su problemática debe ser el punto central de la gestión política y de planificación. 


\section{METROPOLIZACIÓN Y SUSTENTABILIDAD AMBIENTAL}

La cuestión referida a la sustentabilidad urbana, es un fenómeno que ha adquirido carácter de globalidad y por lo tanto se encuentra presente en el contexto urbano latinoamericano. Sin lugar a dudas el flujo de población hacia las metrópolis, ha originado los problemas territoriales analizados anteriormente. Al buscar las causas que han originado el problema, no se debe culpar a los grandes centros urbanos de este fenómeno sino que también se debe referir a la incapacidad de los centros menores y del área rural de retener a su población.

El fenómeno de la crisis de sustentabilidad que presentan las metrópolis tiene una serie de etapas que han venido presentándose a lo largo de la historia urbana. Con respecto a la historicidad de este proceso, R. Morse, señala en su texto "Ensayo y tendencias de la investigación urbana latinoamericana (1965-1970)" que existen diversos estadios. Así se refiere a la crisis de sustentabilidad primaria (1945-1965) y la relaciona con el fracaso de la agricultura intensiva y de las redes urbanas de servicios y agrupaciones; en tanto la crisis de sustentabilidad secundaria (1960-1980) emerge a consecuencia del exceso de flujo migratorio y de los fracasos de las políticas de desarrollo industrial.

Se debe tener en cuenta que la ciudad tiene recursos físicos insuficientes para absorber la creciente población, no solo es débil la política habitacional de los gobiernos sino también la ofrecida por la empresa privada, debido a lo cual los migrantes deben construir "su propia ciudad". Esta es la causa fundamental del déficit de sustentabilidad de las metrópolis; carencia de políticas estatales, imposibilidad del acceso al mercado, segregación del hábitat (construcción de villas miseria) conflictos urbanos sociales, desarticulación de estructuras ciudadanas etc., son reflejo de la escasa sustentabilidad de las grandes ciudades latinoamericanas.

Una de las falencias que presentan las metrópolis y que las caracterizan como centros con débil sustentabilidad, lo constituye el deficiente régimen de organización interpersonal que ellas presentan, reflejada en escasas asociaciones voluntarias por la que surge la informalidad en todos los rubros en especial en el comercio y negocios. Otro matiz de la débil sustentabilidad en las metrópolis es la falta de acceso, oportunidad y seguridad urbana.

Se debe tener presente, además, que la velocidad de la urbanización y por ende de la metropolización, ha sido superior a la tasa de creación de empleos secundarios y terciarios, lo que ha originado migrantes desempleados e informales. Pero si bien es cierto que la población migrante ya se asentó en las grandes metrópolis y es casi imposible revertir este proceso, se hace necesario efectuar un análisis de los principales problemas que se presentan en el medio ambiente urbano, muchos de los cuales son ocasionados por los mismos pobladores y que, sin lugar a dudas, le corresponde a estos mismos habitantes tomar conciencia de ellos a fin de disminuir o en el mejor de los casos tratar de evitarlos o incrementarlos.

Resulta necesario destacar que surge una inconsistencia frente a la problemática planteada, ya que la región latinoamericana dispone de recursos naturales y de un potencial humano que podría sustentar un desarrollo a largo plazo, es decir sustentable. Existe en el espacio latinoamericano un $23 \%$ de la tierra arable del planeta, es decir hay tres veces más tierras arables del promedio que disponen las ciudades del mundo. 
Si pudiéramos efectuar un análisis del medio ambiente urbano debemos recurrir al estudio de la condición que presenta tanto el medio natural urbano como el medio ambiente cultural o construido en las grandes metrópolis, para así asegurar una sustentabilidad de dichos espacios y lo que es más importante, proporcionar una calidad de vida aceptable para sus habitantes.

La concentración demográfica en áreas metropolitanas, además de ejercer presión por territorios, lo que ha ocasionado en la mayoría de ellas, es la expansión exagerada de sus territorios, con la disminución de suelos agrícolas circundantes, produciendo una serie de problemáticas que determinan la Calidad de Vida de sus habitantes.

Por largo tiempo los científicos urbanos han discutido acerca de la conceptualización de la calidad de vida y sus acepciones teóricas. Entre las denominaciones que se han formulado se pueden mencionar, bienestar, comodidad, felicidad, bien común, pero en realidad todas ellas intervienen en el logro de la calidad de vida, pues ésta en sí sugiere una conceptualización mayor.

En el año 1987 los autores D. Olave, E. González y otros plantearon la siguiente conceptualización de Calidad de Vida, en el contexto del proyecto "Metodología básica para definir calidad de vida en ciudades intermedias". Proyecto FONDECYT Santiago de Chile. En esta publicación los autores definieron la Calidad de Vida como: "La satisfacción de necesidades del ser humano, cuyos satisfactores tienen una perspectiva espacial y ambiental, lo que significa que para alcanzar la satisfacción de éstas se involucra el medio físico natural y humano en un tiempo dado. La Calidad de Vida es objetiva, los satisfactores medidos son los comunes para un grupo humano; también es subjetiva o perceptiva ya que la satisfacción aparece como eminentemente individual" (Olave, 1995:73).

Como se puede apreciar, esta acepción de Calidad de Vida se refiere a los aspectos espaciales; es decir, está relacionada en forma directa con los componentes del espacio geográfico, tanto natural como cultural. Bajo esta perspectiva, la calidad de vida se relaciona con la utilización que realiza la población de los recursos naturales y culturales la que la mayoría de las veces es irracional y contraria a la sustentabilidad de ellos.

Existe una clara relación entre el crecimiento de la población y el crecimiento o desarrollo de los recursos naturales, presentándose la mayor parte de las veces una relación aritmética (recursos) y una geométrica (población) en su crecimiento. Uno de los principales recursos afectados y vulnerables son las grandes concentraciones urbanas, lo cual tiene relación con la contaminación atmosférica. Producto de ello y con mayor énfasis en el área urbana, se presenta la polución con altos índices de $\mathrm{CO}^{2}$ producto de la emisión de gases industriales y vehiculares.

Otro elemento del espacio urbano natural afectado, dice relación con la contaminación de los recursos hídricos; Las aguas superficiales que atraviesan las ciudades o las de su periferia ven aumentado la presencia de bacterias coliformes y fecales, lo cual produce una pérdida del oxigeno y por lo tanto de la aireación del agua y de la vida existente. El agotamiento y disminución de las áreas agrícolas, debido a la desmesurada expansión urbana, es otro de los problemas ambientales presentes en las áreas metropolitanas reduciendo y encareciendo cada vez más el abastecimiento de los habitantes.

Le acompaña a estos problemas ambientales urbanos, la existencia de residuos domiciliarios e industriales, los que en su mayoría no reciben el tratamiento adecuado y lo que es más grave origi- 
nan vertederos clandestinos o sin proceso de reciclaje. Se suma a esto la falta de espacios verdes o de esparcimiento. En general, las áreas metropolitanas escasean de áreas verdes y avenidas al aire libre, lo que no permite la recreación y ocupación de áreas de esparcimiento libres.

Se añade a estos problemas ambientales, producto de la extensión territorial, el excesivo gasto de tiempo que ocasionan a sus habitantes los viajes por trabajos, negocios y otros requerimientos particulares, lo cual afecta la salud y el comportamiento familiar.

Sin lugar a dudas, de persistir estas problemáticas ambientales en las grandes áreas urbanas y de no intentarse soluciones que las minimicen, convertirán estos territorios en metrópolis sin sustentabilidad, lo cual debe preocupar a los planificadores e instituciones gubernamentales. Las planificaciones metropolitanas sustentables requieren la inclusión de varios aspectos, los cuales deben ser considerados en forma relacional y a través de estrategias específicas.

El siguiente esquema presenta los elementos que a nuestro juicio debería contemplar una política urbana, sustentable que asegure a sus habitantes una calidad de vida aceptable.

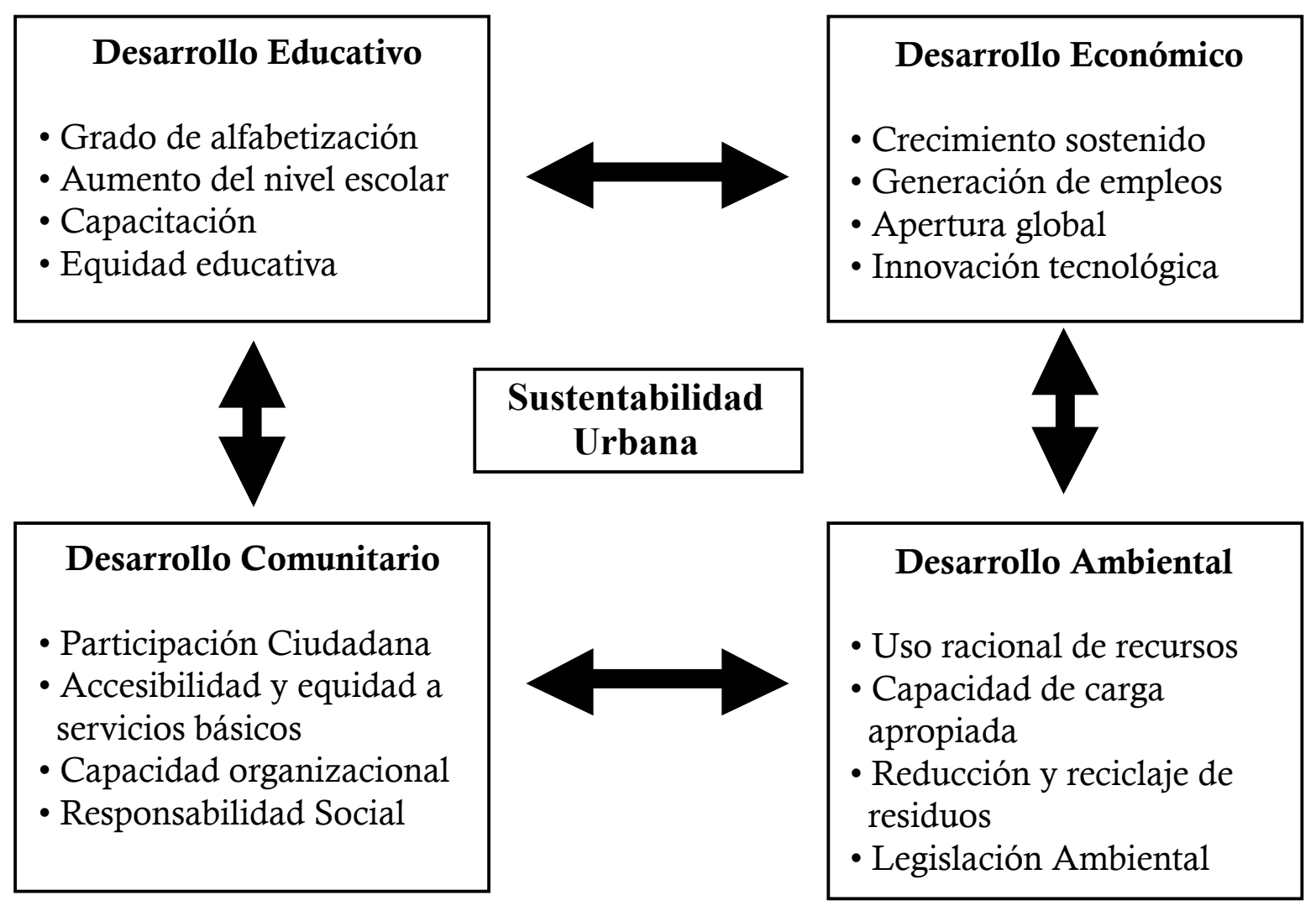

El esquema presenta cuatro factores que inciden en el logro de un área urbana sustentable: educación, desarrollo económico, desarrollo comunitario y desarrollo ambiental.

El primero de ellos es quizás el más significativo ya que permite la conformación de ciudadanos ambientalmente educados y con una marcada sensibilización por los problemas ambientales. La educación, tanto formal como informal, desde la alfabetización hasta la profesionalización de los habitantes conduce a conformar una perspectiva ambientalmente sustentable. De igual modo, el 
desarrollo económico que contemple un crecimiento sostenido de los recursos, acompañado de una generación de empleos y de una innovación tecnológica en el aparato productivo, no solo producirá un desarrollo económico sustentable sino que también le permitirá situar a la metrópoli en un sitio global y de apertura internacional.

El desarrollo comunitario, a su vez, permitirá a los habitantes metropolitanos su participación y accesibilidad en los servicios básicos los cuales generarán responsabilidad social con su entorno. Por último, el desarrollo ambiental urbano traerá consigo el uso racional de los recursos del medio urbano, así como la disminución de los problemas ambientales ya mencionados. Se debe dejar constancia que el logro de una calidad de vida urbana sustentable debe estar respaldado por una rigurosa legislación ambiental que avale los diferentes factores que inciden en la consolidación de una metrópoli sustentable.

\section{METROPOLIZACIÓN Y EDUCACIÓN}

La ciudad metropolitana debe ser caracterizada como una realidad tangible del lugar donde el alumno desarrolla sus experiencias, vivencias y actitudes conducentes a desarrollar con diferentes temáticas educativas que el docente puede plantear y proponer como temática de estudio en el aula.

Entre las temáticas de orden urbano que puede plantear el docente figura en primer lugar la historia urbana, es decir el origen y desarrollo de la metrópoli ya que constituye un ejemplo a ser tratado por los alumnos a través de pequeños estudios de la génesis de la trama urbana (calles, barrios), evolución de las ordenanzas y leyes así como orígenes de la toponimia de la ciudad.

Otra de las temáticas susceptible de ser analizada desde el punto de vista de la sustentabilidad se relaciona con las áreas patrimoniales, su conservación y la evolución de los estilos arquitectónicos. Un itinerario urbano permitirá conocer las áreas urbanas deterioradas o en proceso de renovación para ser conservadas para las generaciones posteriores. Las instituciones industriales es otro tema importante para la sustentabilidad en lo que se refiere a la localización industrial a los desechos industriales y contaminantes atmosféricos.

Los estudios de uso del suelo son importantes para estudiar la sustentabilidad de la metrópoli identificando las áreas de vivienda, áreas verdes y de esparcimiento, áreas comerciales y de servicio, así como posibles áreas de expansión. De gran significado para la comprensión de una metrópoli sustentable resulta la observación y localización de áreas contaminadas tanto por basurales, como sitios baldíos y áreas de desechos domiciliarios. Una especial atención se debe tener con el desarrollo económico de la metrópoli tanto en su economía interna, como en su función económica externa con las áreas vecinas o ciudades menores.

De igual modo, es aconsejable analizar la evolución territorial de la metrópoli, para asegurar y evitar la perdida de suelos agrícolas cercanos a ellas. La vida cotidiana urbana adquiere en las metrópolis una perspectiva interesante de analizar para así comprender problemas tales como aislamiento, incomunicación, perdida de contacto, segregación etc. El estudio y análisis de cada una de estas problemáticas ambientales por parte de los alumnos les permitirá comprender cada uno de ellos y sensibilizarse con el medio urbano metropolitano para así asegurar una calidad de vida sustentable para las generaciones futuras. 


\section{CONCLUSIONES}

Sin lugar a dudas el mundo urbano actual es el de las metrópolis. La metropolización puede considerarse como un fenómeno del mundo global. Frente al deterioro, tanto de las especies rurales como urbanas, requiere de acciones y estrategias que minimicen el deterioro y actúen sobre los elementos motivadores, especialmente sobre aquellos que generan problemas de orden ambiental. La ciudad del siglo XXI plantea a sus habitantes una serie de problemáticas socio - ambientales que afectan tanto a su morfología, estructura y funcionalidades.

La morfología se vincula a su forma de crecimiento / expansión física que produce conflictos al extenderse hacia suelos no adecuados o vulnerables para habitar o a cubrir distancias largas entre sitios de residencia y de trabajo y /o estudio de los habitantes y muchos otros, que los principios de ordenamiento local deben o deberían superar. La morfología urbana es reflejo de las políticas imperantes en un momento dado del crecimiento/desarrollo urbano y el diseño de su plano lo demuestra cartográficamente.

La estructura se refiere a la organización de la ciudad, con base en los usos de suelo que se dan en esta; algunos de ellos incompatibles para que un habitante se sienta satisfecho de vivir en ella. En nuestros días la demanda de los ciudadanos se encamina hacia una ciudad amena, amigable, que disponga de áreas verdes; fácil conectividad; un buen uso del espacio público y con un planteamiento de ciudad segura. El plano regulador y las políticas institucionales deberían velar por una parte, por la adecuada determinación del uso del suelo urbano y delimitar algunas ocupaciones de este recurso que imponen los vaivenes del mercado inmobiliario en nuestros días.

El funcionamiento de la ciudad depende de gran manera del tipo de crecimiento físico que la ciudad experimenta y de los usos de suelo que conforman su estructura. Diversas funcionalidades impartidas por la ciudad se acomodan en este contexto espacial: residenciales, comerciales, industriales, financieras, recreativas y otras. Por otra parte, la ciudad presenta una serie de conflictos sociales vinculados por ejemplo, a demandas por viviendas y empleos; mientras mayor es el tamaño de la ciudad la cantidad de situaciones vinculadas a segregación social, pobreza y delincuencia aumentan surgiendo como escenarios difíciles de controlar. Así mismo, problemáticas ambientales como polución, contaminación de aguas; deshechos y otros, requieren de un manejo y gestión en el momento pertinente para no provocar impactos de mayores dimensiones que afectan a la ciudadanía y vecinos.

En lo que respecta a los espacios urbanos metropolitanos se deben efectuar acciones que contemplen aspectos: educativos, económicos, sociales y ambientales. De este modo será posible aspirar al logro de una sustentabilidad urbana y ambiental. La educación y en especial la educación geográfica ambiental, se transforma en una herramienta eficaz para que los docentes de todos los niveles educativos realicen acciones pedagógicas de carácter ambiental que conduzcan a la formación de ciudadanos ambientalmente educados. 


\section{BIBLIOGRAFÍA}

Durán, D. et al. (1996). Los cambios mundiales y la enseñanza de la geografia. Primera reimpresión. Buenos Aires: Editorial Troquel.

Durán, D. (2000). El crepúsculo de la buena Tierra. Raíces geográficas de la educación ambiental. Colección Lugar Docente. Buenos Aires: Lugar editorial.

Durán, D. (2005). El concepto de lugar en la enseñanza. Fundación Educa Ambiente. Recuperado de www.ecoportal.net/content/view/full/30984 [Consulta: 2010, 22 de noviembre].

Durán, D. (2010). Las dimensiones de la sustentabilidad. Fundación Educa Ambiente. Recuperado de http://www.ecoportal.net/content/view/full/91572 [Consulta: 2010, 22 de noviembre].

Gallastegui J. (2009). Espacios para una geografia social, humanistica y científica. Chile: Universidad de Playa Ancha.

González M., I. (2002). La ciudad sostenible. Planificación y Teoría de Sistemas. España: Universidad de León.

González, E. (1989). La metropolización de América Latina. Revista Geográfica IPGH-OEA (110).

Kent, R. (2006). Latin America: Regions and People. New York: The Guilford Press.

Lidstone, J. y Willims, M. (Eds). (2006). Geographical education in a changing world. Past experience, current trends and future challenges. The GeoJournal Library, Volume 85. The Netherlands: Springer.

Muñiz, O. y Boehm, R. (Eds). (2009). Geography Education Pan American Perspectives. The Gilbert M. Grosvenor Center for Geographic Education. Texas State University, San Marcos. A Volume in the International Geography Education Series. Estados Unidos: Edit. Capital Printing Co.

Olave D. y González E. (1995). Conceptos Básicos de Calidad de Vida. Serie Investigación y Docencia. Chillan: Universidad del Bio-Bio.

Olave, D. et al. (2001). Metodología Básica para medir Calidad de Vida en ciudades intermedias de Chile. Revista Geográfica IPGH-OEA (129).

Ruiz, M. del C. et al. (2008). La Geografía en la enseñanza de la educación ambiental. Novedades Educativas, 20(212).

Souto, X. M. (Ed). (2007). Didáctica Geográfica. Segunda Época (9).

Valverde J. A. (1988) Valorar el medio urbano en el proceso de enseñanza-aprendizaje. Madrid: IV Jornadas de Didáctica de la Geografía. 